\title{
EFEITOS DO TERMO DE AJUSTAMENTO DE CONDUTA EM MATÉRIA AMBIENTAL E SEUS REFLEXOS NAS ESFERAS CÍVEL E ADMINISTRATIVA
}

\author{
Letícia Nalin Alves, Fábio Ferreira Morong \\ Universidade do Oeste Paulista - UNOESTE, Curso de Direito, Presidente Prudente, SP, E-mail: \\ leticianalin@hotmail.com
}

\section{RESUMO}

A Constituição brasileira prevê a responsabilização dos agentes degradadores do meio ambiente nas esferas civil, administrativa e criminal. O Termo de Ajustamento de Conduta (TAC) em matéria ambiental previsto no ordenamento jurídico brasileiro visa uma rápida solução das lides. Assim, este trabalho objetiva realizar um estudo sobre o TAC em matéria ambiental, com enfoque na sua capacidade de diminuir as demandas judiciais e garantir uma rápida reparação ao meio ambiente degradado, bem como, estudar seus reflexos nas esferas: cível e administrativa. O método aplicado foi o dedutivo legal, baseado na interpretação da legislação, jurisprudências e doutrinas. Conclui-se que o Termo de Ajustamento de Conduta consagra a transação, colocando fim ou prevenindo um litígio, promovendo a reparação do dano ambiental ou recuperação da área já degrada de forma célere. Observou-se, também, uma interdependência entre as esferas cível e administrativa.

Palavras-chave: Termo de Ajustamento de Conduta (TAC), meio ambiente, transação, esfera civil, esfera administrativa.

\section{EFFECTS OF THE CONDUCT ADJUSTMENT AGREEMENT IN ENVIRONMENTAL MATTERS AND THEIR REFLECTIONS IN SPHERES CIVIL AND ADMINISTRATIVE}

\begin{abstract}
The Brazilian Constitution provides for the accountability of degrading agents of the environment in civil, administrative and criminal spheres. The Conduct Adjustment Agreement (TAC) in environmental matters provided for in the Brazilian legal system seeks a quick solution of environmental litigations. Thus, this study aims to conduct a study on the TAC in environmental matters, with a focus on their ability to reduce claims and ensure timely repair of the degraded environment, as well as study their reflections in 2 spheres: civil and administrative. The method applied was the legal deductive, based on the interpretation of legislation, jurisprudence and doctrine. It is concluded that the Conduct Adjustment Agreement establishes the transaction, ending or preventing a dispute, promoting the repair of environmental damage and recovery of the area already degraded swiftly. There was also an interdependence between civil and administrative levels.
\end{abstract}

Keywords: Conduct Adjustment Agreement (TAC), environment, transaction, sphere civil, sphere administrative. 


\section{INTRODUÇÃO}

A questão ambiental está constantemente em pauta nos debates sociais da atualidade, sendo um dos temas de maior repercussão. Em sua obra Morong (2014) destaca que as ações humanas sempre afetaram a evolução do planeta e seus ciclos naturais. $O$ ser humano através de ações transformadoras do meio em que vive, visando uma melhor qualidade de vida, muitas vezes produz um desequilíbrio ecológico.

Ao cidadão é garantido usufruir o meio ambiente que o cerca, porém essa utilização deve ser pautada na racionalidade, garantindo que essa intervenção humana no ambiente não lhe provoque degradação. A Constituição da República Federativa do Brasil em seu artigo 225, "caput", destaca o meio ambiente como um bem de uso comum, impondo ao Poder Público e a coletividade a responsabilidade por sua defesa e preservação. Enquanto no parágrafo 2ㅇ prevê a obrigatoriedade do agente causador de um dano ambiental recuperar a área degradada, informando ainda, que os que procederem a atividades e condutas lesivas ao meio ambiente sofrerão sanções penais, cíveis e administrativas, conforme §3으 do artigo 225 , da referida Carta Magna.

A tríplice responsabilização garante ampla proteção ecológica, seja no sentido de prevenir o dano ambiental, promover a recuperação natural, por meio de indenização em pecúnia, ou até mesmo através da repressão à atividade nociva ao meio ambiente (Milaré, 2001). Dessa forma, o legislador procurou garantir uma ampla proteção ao meio ambiente, porém em razão do demorado trâmite processual, do afogamento que o Judiciário Nacional se encontra e da burocracia institucional brasileira nos procedimentos administrativos, muitas vezes essa extrema proteção a este bem jurídico inviabiliza a rápida recuperação de áreas degradas e/ou prevenção de dano ambiental, causando graves danos à coletividade.

Visando a rápida solução dessas demandas, foi inserido no ordenamento jurídico brasileiro o Termo de Ajustamento de Conduta (TAC) em matéria ambiental, previsto no artigo 113 do Código de Defesa do Consumidor (Lei 8.078/90), que acrescentou o § 60 ao artigo 5으 da Lei 7.347/85. O TAC é um título executivo extrajudicial, que busca promover um desenvolvimento sustentável, através de um ajuste entre o órgão público legitimado a propor ação civil pública ou coletiva, e o agente degradador, mediante cominações. A legitimidade do Ministério Público para propor o TAC ambiental decorre da própria Constituição Federal em seu artigo 129, inciso III, bem como, da Lei da Ação Civil Pública (artigo 5o, inciso I, da Lei no 7.347/85). Posteriormente, a Medida Provisória no 2163/2001 acrescentou a Lei 9.605/98 (Lei dos Crimes Ambientais) o artigo 79-A, que confere aos órgãos ambientais integrantes do SISNAMA (Sistema Nacional do Meio Ambiente) autorização para firmarem o Termo de Compromisso Ambiental (TCA). Segundo Silva e Araújo (2014) o TCA tem como objetivo restituir o dano ambiental causado de forma integral, através da compensação ecológica, e somente na impossibilidade de restauração da área degradada é que a indenização pecuniária se impõe.

Sendo assim, o presente trabalho buscou estudar o Termo de Ajustamento de Conduta na esfera ambiental e discutir seus reflexos nas esferas de responsabilização cível e administrativa.

\section{METODOLOGIA}

O presente trabalho empregou pesquisas à legislação nacional, jurisprudências e doutrinas relevantes na matéria objeto de estudo. Utilizando o método dedutivo para sistematizar os dados coletados, a fim de cumprir o objetivo proposto. 


\section{TERMO DE AJUSTAMENTO DE CONDUTA AMBIENTAL}

O Termo de Ajustamento de Conduta está previsto no $\S 60$ do artigo 5o da Lei 7.347/85, como um título executivo extrajudicial, que na área ambiental, compreende em um compromisso de ajustamento de conduta dos agentes degradadores do meio ambiente às exigências da lei.

Os órgãos públicos legitimados a firmar este compromisso são os descritos nos incisos do artigo 5o da Lei da Ação Civil Pública. Entre estes o Ministério Público é o que merece maior destaque.

Assim, Milaré (2001) afirma que os TAC são destinados a prevenir o litígio, no sentido de não haver a propositura da ação civil pública, ou colocar um fim em uma existente, garantindo ao legitimado um título executivo extrajudicial ou judicial, que torna a obrigação líquida e certa.

Neste sentido, Rodrigues (2015) destaca que os TAC trazem obrigações de fazer e de não fazer, além de preverem pagamento em pecúnia, referente às multas civis que são impostas nos mesmos.

Os termos de ajuste de conduta, como anteriormente dito, são títulos executivos extrajudiciais, mas podem ser levados à homologação judiciária. É indispensável estar previsto no ajuste à total reparação do dano, em razão da natureza indisponível deste direito transindiviudal, além da pena em caso de descumprimento. Rodrigues (2015) ainda destaca que, "o órgão público deve ter o cuidado de colocar no TAC a obrigação com todas as suas especificações, de forma que a sua efetivação não dependa de nenhum ato posterior ou existente fora do corpo do termo de ajuste".

Assim, o Termo de Ajustamento de Conduta ambiental é um instrumento jurídico que consagra a transação, colocando fim a uma ação civil pública previamente existente ou prevenindo um litígio, ainda na fase do inquérito civil público, promovendo com isso a reparação do dano ambiental ou recuperação da área já degrada de uma forma mais célere do que por longos processos judiciais.

\section{TERMO DE COMPROMISSO AMBIENTAL}

A Lei 9.605/90 (Lei de Crimes Ambientais) definiu as sanções penais e administrativas em matéria ambiental, e através da Medida Provisória 2.163/2001, foi incluído nas disposições finais desta lei o artigo 79-A, que autoriza os órgãos competentes a firmarem termo de compromisso ambiental (TCA) com os responsáveis por ilícitos ambientais.

O artigo 79-A da Lei 9.605/98 prescreve a competência ambiental para celebrar o termo de compromisso e as diretrizes específicas que fazem parte do citado instrumento, senão vejamos:

Art. 79-A. Para o cumprimento do disposto nesta Lei, os órgãos ambientais integrantes do SISNAMA, responsáveis pela execução de programas e projetos e pelo controle e fiscalização dos estabelecimentos e das atividades suscetíveis de degradarem a qualidade ambiental, ficam autorizados a celebrar, com força de título executivo extrajudicial, termo de compromisso com pessoas físicas ou jurídicas responsáveis pela construção, instalação, ampliação e funcionamento de estabelecimentos e atividades utilizadores de recursos ambientais, considerados efetiva ou potencialmente poluidores.

$\S 1^{\text {으 }} \mathrm{O}$ termo de compromisso a que se refere este artigo destinar-se-á, exclusivamente, a permitir que as pessoas físicas e jurídicas mencionadas no caput possam promover as necessárias correções de suas atividades, para o atendimento das exigências impostas pelas autoridades ambientais competentes, sendo obrigatório que o respectivo instrumento disponha sobre: 
I - o nome, a qualificação e o endereço das partes compromissadas e dos respectivos representantes legais;

II - o prazo de vigência do compromisso, que, em função da complexidade das obrigações nele fixadas, poderá variar entre o mínimo de noventa dias e o máximo de três anos, com possibilidade de prorrogação por igual período;

III - a descrição detalhada de seu objeto, o valor do investimento previsto e o cronograma físico de execução e de implantação das obras e serviços exigidos, com metas trimestrais a serem atingidas;

IV - as multas que podem ser aplicadas à pessoa física ou jurídica compromissada e os casos de rescisão, em decorrência do nãocumprimento das obrigações nele pactuadas;

V - o valor da multa de que trata o inciso IV não poderá ser superior ao valor do investimento previsto;

$\mathrm{VI}$ - o foro competente para dirimir litígios entre as partes.

Portanto, o Termo de Compromisso Ambiental é um título executivo extrajudicial que tem por finalidade permitir que os agentes que causaram ou venham a causar degradação ambiental, possam efetuar as necessárias adequações de suas atividades às exigências da lei ambiental. Promovendo o ajuste da atividade econômica exercida pelas pessoas físicas e jurídicas, quando atuam no meio ambiente como agentes degradadores.

\section{REFLEXOS DO TERMO DE AJUSTAMENTO DE CONDUTA AMBIENTAL NAS ESFERAS CIVEL E ADMINISTRATIVA.}

A tríplice responsabilização do agente degradador do meio ambiente garante ampla proteção ecológica. Porém, firmado um termo de ajuste de conduta, surge a polêmica sobre os efeitos deste nas três esferas de responsabilização envolvidas: cível, administrativa e penal; uma vez que existe a independência entre estes ramos do direito.

Como mencionado anteriormente, para Milaré (2001) o TAC em matéria ambiental é destinado a prevenir o litígio, no sentido de não haver a propositura da ação civil pública, ou colocar um fim em uma existente, garantindo ao legitimado um título executivo extrajudicial ou judicial, que torna a obrigação líquida e certa.

Porém, é certo que um termo de ajustamento de conduta em matéria ambiental firmado pelo Ministério Público somente determinará o arquivamento de um inquérito civil após o colegiado competente entender que o compromisso é satisfatório. Caso o colegiado conclua que o acordo está aquém do ideal poderá determinar somente o encerramento de partes da investigação ministerial. Pode ser ainda, que após a revisão seja determinada a propositura de uma ação civil pública por outro membro da instituição. Sendo um TAC firmado em uma ação civil pública em curso, a mesma será extinta (MAZZILLI, 2015).

Quanto ao reflexo na área cível de um termo de ajustamento de conduta ambiental firmado entre o autor do dano e um colegitimado do Ministério Público competente, o Conselho Superior do Ministério Público Paulista, por exemplo, editou a Súmula no 30, que diz:

A formalização de compromisso de ajustamento de conduta entre o autor de dano ou sua ameaça a interesses difusos ou coletivos e órgão público colegitimado permite o arquivamento do inquérito civil, desde que o termo atenda à defesa dos bens tutelados e contenha todos os requisitos de título executivo extrajudicial, procedendo-se nos moldes do art. 86, § 20 no Ato 484/2006-CPJ, após a homologação do arquivamento. 
Portanto, pode-se notar que mesmo um TAC firmado por um colegitimado do Mistério Público pode determinar o arquivamento de um inquérito civil em relação à mesma matéria sobre a qual foi firmado o compromisso. Cabendo ao Ministério Público fiscalizar, posteriormente, o cumprimento do ajustado.

Quanto aos reflexos do TAC na esfera administrativa encontra-se a na própria legislação nacional a interligação entre esferas cível e administrativa. O que pode ser observado no conteúdo do artigo 146, §§ 3으 e 4ㅇ do Decreto no 6.514/08que diz:

Artigo 146, $\S 3^{\circ}$ O termo de compromisso terá efeitos na esfera civil e administrativa. $\S 4^{\circ}$ O descumprimento do termo de compromisso implica: I - na esfera administrativa, a imediata inscrição do débito em Dívida Ativa para cobrança da multa resultante do auto de infração em seu valor integral; e II - na esfera civil, a imediata execução judicial das obrigações assumidas, tendo em vista seu caráter de título executivo extrajudicial.

Assim, a interdependência entre as esferas cível e administrativa torna-se clara, uma vez que adotadas as medidas saneadoras no âmbito cível inexistem penalidades administrativas. Neste sentido ensina Milaré (2007 apud HASEMANN, 2010), a penalidade administrativa é desnecessária enquanto ocorre a formalização do TAC, bem como no prazo de sua vigência, enquanto houver o integral cumprimento de suas cláusulas.

\section{CONCLUSÃO}

Com o presente artigo objetivou-se realizar um estudo sobre o TAC em matéria ambiental, com enfoque na sua capacidade diminuir as demandas judiciais e garantir uma rápida reparação ao meio ambiente degradado, bem como, estudar seus reflexos nas esferas: cível e administrativa.

Constatou-se que o Termo de Ajustamento de Conduta em matéria ambiental é um instrumento jurídico viável para dirimir as lides ambientais de uma forma mais célere do que por longos processos judiciais, provendo um ajustamento de conduta dos agentes degradadores do meio ambiente às exigências legais. Garantindo ao meio ambiente uma rápida reparação ou mesmo evitando uma possível degradação.

Verificou-se também que apesar do Termo de Ajustamento de Conduta em matéria ambiental e o Termo de Compromisso Ambiental constituírem meios extrajudiciais que visam de forma célere propor a reparação do meio ambiente degrado, através de um instrumento jurídico firmado entre os órgãos legitimados e o agente degradador, os órgãos que estão legitimados para proporem referidos Termos são diferentes. O Termo de Ajustamento de Conduta pode ser proposto pelo Ministério Público, Associações e Defensoria Pública, enquanto que o Termo de Compromisso Ambiental é de competência dos órgãos integrantes do sistema SISNAMA. Sendo assim, Termo de Ajustamento de Conduta em matéria ambiental não pode ser confundido com Termo de Compromisso Ambiental.

De outro lado, observou-se ainda, que firmado um Termo de Ajustamento de Conduta em matéria ambiental em uma ação civil pública, as consequências administrativas devem cessar, uma vez que adotadas as medidas saneadoras no âmbito cível não existem razões para se adotarem penalidades administrativas.

Quanto os reflexos de uma TAC em matéria ambiental em um inquérito civil público, conclui-se que, desde que o compromisso firmado entre o agente degradador e o órgão legitimado atendam aos interesses transindividuais de forma satisfatória à sociedade e às exigências da legislação ambiental, o inquérito civil que versa sobre a matéria acordada deverá ser arquivado, mesmo quando este foi proposto por um colegitimado do Ministério Público. Caso o compromisso não contemple todas as exigências legais para a lide em questão o inquérito deverá prosseguir quanto aos requisitos restantes. O mesmo entende-se para uma ação civil pública em 
andamento. Sendo o TAC em matéria ambiental firmado na ação civil pública em curso, após homologado, a referida ação deverá ser julgada extinta.

Sobrevindo um TAC em matéria ambiental firmado por um ente legitimado versando sobre os mesmos interesses discutidos em uma ação civil pública ambiental entende-se que esta deve ser extinta. Porém, cabe ao Ministério Público a fiscalização em relação ao cumprimento do TAC em matéria ambiental.

\section{REFERÊNCIAS}

FERNANDES, M. B. Termo de Ajustamento de Conduta Ambiental e seus Efeitos na Responsabilização Penal. In: Wunderlich, A. et al (Org.). Temas Críticos em Direito, 1 a edição, Guaíba: Sob Medida, 2012, v. 2.

MAZZILLI, H. N. A defesa dos interesses difusos em juízo, 28a edição, São Paulo: Saraiva, 2015.

MILARÉ, E. Direito do ambiente: doutrina, prática, jurisprudencia, glossário, 2a edição, São Paulo: Revista dos Tribunais, 2001.

MILARÉ, É. Direito do ambiente: a gestão ambiental em foco, 2007. In: HASEMANN, A. M. O termo de Ajustamento de conduta ambiental e o principio da obrigatoriedade. Revista Jus Navigandi, Teresina, ano 15, n. 2715, 2010.

MORONG, F. F. El régimen jurídico de las licencias y autorizaciones ambientales en España y Brasil: análisis jurídico-ambiental derivado de los aspectos novedosos de la normativa general de laUniónEuropea sobre prevención y control integrados de lacontaminación. 1. ed. Salamanca: EdicionesUniversidad de Salamanca, 2014.

Rodrigues, M. A. Direito ambiental esquematizado,2ª edição, São Paulo: Saraiva,2015.

SILVA, A. C.; ARAÚJO, E. L. Termo de compromisso ambiental: avanço ou retrocesso? Revista Jus Navigandi, Teresina, ano 19, n. 4059, 2014. 